\title{
Identification of long non-coding RNA 00312 and 00673 in human NSCLC tissues
}

\author{
QIAN TAN ${ }^{1,2}$, YALAN YU $^{1,2}$, NANDI LI ${ }^{1,2}$, WEI JING ${ }^{1,2}$, HU ZHOU $^{1,2}$, SHILI QIU $^{1,2}$ \\ CHUNZI LIANG ${ }^{1,2}$, MINGXIA YU ${ }^{1,2}$ and JIANCHENG TU ${ }^{1,2}$ \\ ${ }^{1}$ Department of Laboratory Medicine, Clinical Laboratory of Medicine and Center for Gene \\ Diagnosis, Zhongnan Hospital, Wuhan University; ${ }^{2}$ School of Laboratory Medicine, Hubei \\ University of Traditional Chinese Medicine, Wuhan, Hubei 430071, P.R. China
}

Received June 17, 2016; Accepted June 9, 2017

DOI: $10.3892 / \mathrm{mmr} .2017 .7196$

\begin{abstract}
Non-small cell lung cancer (NSCLC) is a fatal disease to human health. Despite the advanced progresses in cancer therapy during the past decades, NSCLC still remains the leading cause of cancer death worldwide. The long non-coding RNAs (lncRNAs) recently have been considered as key regulators of tumor malignant. Previous studies identified that long non-coding RNAs, linc00312 and linc00673 are markedly associated with lung cancer. However, current understanding of the two lncRNAs involving in NSCLC remains unclear. The aim of the present study was to profile their expression and clinicopathological significance in 76 patients' NSCLC tissues compared to non-tumor tissues using reverse transcription-quantitative polymerase chain reaction. Data have indicated that the linc00312 expression level was significantly decreased in NSCLC tissues $(\mathrm{P}<0.001)$, while a higher linc00673 level has been detected in the same tumor tissues $(\mathrm{P}<0.01)$. In addition, the low expression of linc00312 was associated with the Tumor-Node-Metastasis stage of NSCLC $(\mathrm{P}<0.05)$, whereas the high expression of linc00673 was related with the histological types of NSCLC $(\mathrm{P}<0.05)$. In conclusion, lncRNA 00312 and 00673 may serve as potential novel biomarkers for lung cancer early diagnosis, which may play a vital role in treatments of NSCLC.
\end{abstract}

Correspondence to: Professor Jiancheng Tu, Department of Laboratory Medicine, Clinical Laboratory of Medicine and Center for Gene Diagnosis, Zhongnan Hospital, Wuhan University, 169 Dong Hu Road, Wuhan, Hubei 430071, P.R. China

E-mail: jianchengtu@whu.edu.cn

Key words: long non-coding RNA, non-small cell lung cancer, linc00312, linc00673, reverse transcription-quantitative polymerase chain reaction

\section{Introduction}

Lung cancer is one of the most common malignant cancers in China and with the highest mortality and low five-year survival rate of $16.6 \%$ (1). Non-small cell lung cancer (NSCLC) which accounts for $\sim 85 \%$ of lung cancer includes lung adenocarcinoma, lung squamous and large cell lung cancer (2). The most common types of NSCLC are lung adenocarcinoma (ADC) and lung squamous cell cancer (SCC) (3). The effective treatment for the patients with early-stage NSCLC remains to be complete surgical resection, indicating that the disease is medically operable. The effectiveness of surgery, however, is limited by high rates of distant recurrence because of the presence of metastatic diseases (4). Therefore, it is necessary to exploit the underlying mechanisms during the development of NSCLC and find new biological biomarkers with high sensitivity and specificity to improve the early diagnosis and treatment of NSCLC.

Long non-coding RNAs (lncRNAs) are evolutionarily conserved non-coding RNA that are $>200$ nucleotides with no protein-coding capacity (5). Accumulating research has demonstrated that lncRNAs participate in multiple cancers through diverse pathogenic processes, such as cell differentiation, proliferation and invasion $(6,7)$. The potential regulation pattern of lncRNAs to modulate the expression of associated genes may be at transcriptional, post-transcriptional and epigenetic levels (8). In previous years, abundant lncRNAs have been reported to have critical roles in the development of NSCLC, including some upregulated lncRNAs like MALAT1 (9), H19 (10), PVT1 (11) and UCA1 (12), and downregulated ones such as GAS5 (13) and MEG3 (14), Spry4-IT1 (15) and BANCR (16). Due to the advances of high throughout technology, such as microarray and RNA-sequencing, numerous lncRNAs have been detected and profiled in lung cancer. It is well established that the expression patterns of lncRNAs are different in lung adenocarcinoma LAD and lung squamous cell carcinoma (LSCC).

The long intergenic non-coding RNA linc00312, also called NAG7, located at Ch3p25.3 and originally identified in nasopharyngeal carcinoma as a novel putative tumor suppressor gene. Previous studies have revealed that linc00312 significantly declined in NPC tissues compared 
Table I. Correlation between clinicopathological factors and linc00312 and linc00673 expression levels in non-small cell lung cancer patients.

\begin{tabular}{|c|c|c|c|c|c|c|c|}
\hline \multirow[b]{2}{*}{ Variable } & \multirow[b]{2}{*}{ Cases (n) } & \multicolumn{3}{|c|}{ Linc00312 expression } & \multicolumn{3}{|c|}{ Linc00673 expression } \\
\hline & & Low & High & P-value & Low & High & P-value \\
\hline Gender & & & & 0.111 & & & 0.289 \\
\hline Male & 57 & 32 & 25 & & 31 & 26 & \\
\hline Female & 19 & 6 & 13 & & 7 & 12 & \\
\hline Age (years) & & & & 0.819 & & & 0.819 \\
\hline$\leq 60$ & 36 & 17 & 19 & & 18 & 18 & \\
\hline$>60$ & 40 & 21 & 19 & & 21 & 19 & \\
\hline Smoking & & & & 0.217 & & & 0.217 \\
\hline Never & 24 & 9 & 15 & & 11 & 13 & \\
\hline Yes & 52 & 29 & 23 & & 27 & 25 & \\
\hline Tumor size $(\mathrm{cm})$ & & & & 0.176 & & & 0.419 \\
\hline$\leq 3$ & 18 & 6 & 12 & & 7 & 11 & \\
\hline$>3$ & 58 & 32 & 26 & & 31 & 27 & \\
\hline Histological stage & & & & $0.023^{\mathrm{a}}$ & & & 0.165 \\
\hline I & 40 & 18 & 22 & & 16 & 24 & \\
\hline II & 12 & 3 & 9 & & 8 & 4 & \\
\hline III & 24 & 17 & 7 & & 14 & 10 & \\
\hline T-stage & & & & 0.392 & & & 0.392 \\
\hline 1 & 18 & 6 & 12 & & 7 & 11 & \\
\hline 2 & 40 & 21 & 19 & & 21 & 19 & \\
\hline 3 & 8 & 3 & 5 & & 4 & 4 & \\
\hline 4 & 10 & 6 & 4 & & 6 & 4 & \\
\hline Regional lymph nodes & & & & 0.08 & & & 0.674 \\
\hline No & 52 & 24 & 28 & & 25 & 27 & \\
\hline N1 & 9 & 3 & 6 & & 4 & 5 & \\
\hline $\mathrm{N} 2$ & 15 & 11 & 4 & & 9 & 6 & \\
\hline Histological differentiation & & & & 0.685 & & & 0.511 \\
\hline Poorly & 15 & 6 & 9 & & 6 & 9 & \\
\hline Moderately-poorly & 8 & 6 & 2 & & 6 & 2 & \\
\hline Moderately & 47 & 23 & 24 & & 24 & 23 & \\
\hline Moderately-well & 3 & 2 & 1 & & 1 & 2 & \\
\hline Well & 3 & 1 & 2 & & 1 & 2 & \\
\hline Left-right & & & & 0.167 & & & 0.357 \\
\hline Left & 35 & 14 & 21 & & 15 & 20 & \\
\hline Right & 41 & 24 & 17 & & 23 & 18 & \\
\hline $\mathrm{ADC} / \mathrm{SCC}$ & & & & 1.000 & & & $0.037^{\mathrm{a}}$ \\
\hline $\mathrm{ADC}$ & 43 & 21 & 22 & & 17 & 26 & \\
\hline $\mathrm{SCC}$ & 33 & 17 & 16 & & 21 & 12 & \\
\hline
\end{tabular}

${ }^{\text {a }}<0$.05. ADC, adenocarcinoma; SCC, squamous cell carcinoma.

with non-cancerous nasopharyngeal epithelium tissues $(17,18)$. However, further study has demonstrated that linc00312 was reduced in NSCLC tissues compared to non-tumorous tissues (19). A recent study (20) has been reported that long intergenic RNA linc00673, which located at Ch17q25.1, could also serve a crucial role in NSCLC progression and may be a potential tumor biomarker for patients NSCLC. In the present study, the expression levels of lncRNA linc00312 and linc00673 in NSCLC patients' tissues were investigated and expect to estimate the association between the expression levels and clinical features.

In the current study, the authors have analyzed the expression levels of linc00312 and linc00673 in 76 tumor tissues from NSCLC patients and paired non-cancerous lung tissues. In addition, the correlation of linc00312 and linc00673 with a variety of clinicopathological parameters were evaluated. 


\section{Materials and methods}

Tissue samples and cell lines. A total of 76 NSCLC tissues (including 43 LAD and 33 LSCC) and their morphologically normal tissues (located $>3 \mathrm{~cm}$ away from the tumor) were collected from Zhongnan Hospital of Wuhan University (Wuhan, China) between October 2014 and January 2016. The study was approved by the Medical Ethical Committee of the Zhongnan Hospital of Wuhan University. Patients who underwent surgical resection without any previous anticancer treatment and finally diagnosed as primary NSCLC according to the postoperative histopathological findings were used as experimental subjects. All tissue samples were snap-frozen in liquid nitrogen and stored at $-80^{\circ} \mathrm{C}$ until total RNA extraction. The use of the tissue samples for the experiment was under the informed consent and agreement of all enrolled patients. All patients were pathologically confirmed by clinical histological features such as histological type and Tumor-Node-Metastasis (TNM). All the patients' clinical and pathological features are presented in Table I.

Four NSCLC cell lines (A549, SPC-A-1, H1299 95-D) and human embryonic lung fibroblasts (HELF) were provided by the School of Public Health of Wuhan University (Wuhan, China). All cell lines were cultured in Dulbecco's modified Eagle's medium (HyClone; GE Healthcare, Chalfont, UK) added with $10 \%$ (v/v) fetal bovine serum, $100 \mathrm{IU} / \mathrm{ml}$ penicillin and streptomycin $(100 \mathrm{U} / \mathrm{ml})$, then incubated at $37^{\circ} \mathrm{C}$ in a humidified chamber with $5 \%(\mathrm{v} / \mathrm{v}) \mathrm{CO}_{2}$. The cell RNA was extracted when all the survival rate of the cells was $\sim 85 \%$, as observed under a light microscope, and experiments were repeated three times.

RNA isolation and reverse transcription-quantitative polymerase chain reaction $(R T-q P C R)$. Total RNA was extracted from the tissues and cell lines using TRIzol reagent (Invitrogen; Thermo Fisher Scientific, Inc., Waltham, MA, USA) according to the manufacturer's instructions (1 $\mathrm{ml}$ TRIzol/80 mg tissue). The RT-qPCR assay was conducted to detect the level of RNA transcripts. Briefly, reaction mixture (20 $\mu \mathrm{l}$ ) containing $1 \mu \mathrm{g}$ total RNA was reverse transcribed to cDNA by using PrimeScript RT reagent kit with gDNA Eraser (Takara Biotechnology Co., Ltd., Dalian, China). RT-qPCR was performed using the SYBR Premix Ex Taq II real-time PCR kit (Takara Biotechnology Co., Ltd.) in a $20 \mu \mathrm{l}$ reaction volume, which contained $10 \mu \mathrm{l}$ SYBR Premix Ex Taq II, $0.8 \mu 1$ of each of forward and reverse primers, $2 \mu$ l diluted cDNA template and appropriate amounts of sterile distilled water. Thermocycling conditions were as follows: Initial denaturation at $95^{\circ} \mathrm{C}$ for $30 \mathrm{sec}$, followed by 40 cycles of denaturation at $95^{\circ} \mathrm{C}$ for $5 \mathrm{sec}$, annealing at $63.3^{\circ} \mathrm{C}$ for $30 \mathrm{sec}$ and elongation at $72^{\circ} \mathrm{C}$ for $30 \mathrm{sec}$. The sequences of the PCR primers were as follows: Linc00673, forward 5'-CTCGGACCTTAG GGCTGTTG-3', reverse 5'-GGCTGCAATGAACGACAG TG-3'; linc00312, forward 5'-GGTTCTTCTTAATCTGGC TGTTG-3', reverse 5'-TTATTGGCTTGGTTCGCTTGTC-3'; and GAPDH, forward 5'-GGTCTCCTCTGACTTCAACA-3' and reverse 5'-GTGAGGGTCTCTCTCTTCCT-3'. GAPDH as an internal control was used to normalize the data to determine the relative expression of the target genes. The reaction conditions were set based on the kit instructions. Following
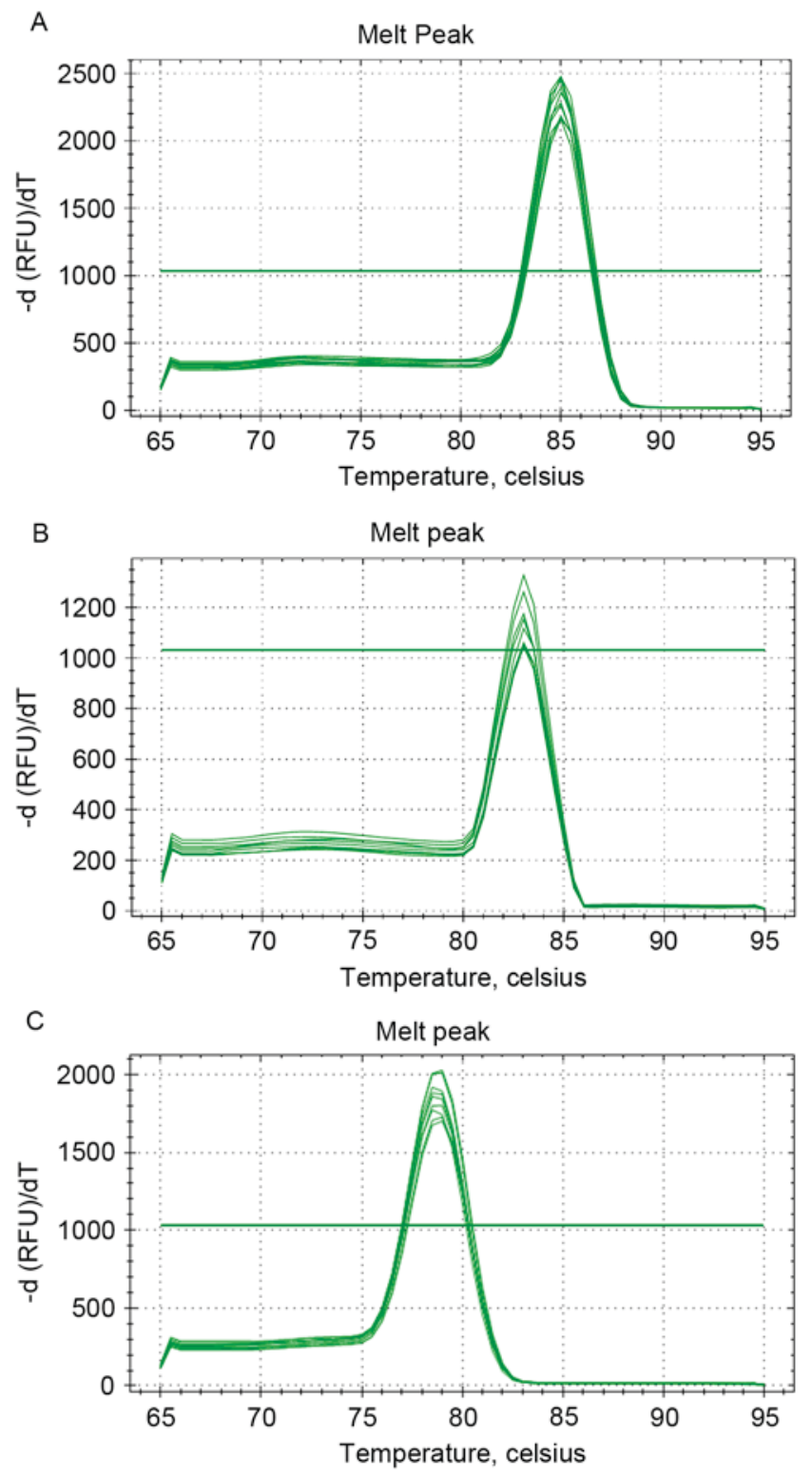

Figure 1. The figures of melt peak in melting curve analysis: (A) Endogenous control, GAPDH, (B) linc00673, (C) linc00312. LincRNA, long intergenic non-coding RNA.

completion of the reaction, the amplification curve and melting curve were analyzed to measure the specificity of the amplified products method. The relative expression of each lncRNA was calculated using the comparative cycle threshold method $\left(2^{-\Delta \Delta \mathrm{Cq}}\right)(21)$.

Statistical analysis. All statistical analyses were performed using the SPSS software (version, 17.0; SPSS, Inc., Chicago, IL, USA). Paired-sample Student's t-test and Wilcoxon test were applied to compare the expression levels of linc00312 and linc00673 between NSCLC tissues and normal tissues. The association between the expression levels and clinicopathological factors was analyzed by the two-sided chi-square test. A receiver operating characteristic (ROC) curve was applied to evaluate the diagnostic value. Data are presented as mean \pm standard error of the mean. $\mathrm{P}<0.05$ was considered to indicate a statistically significant difference. 

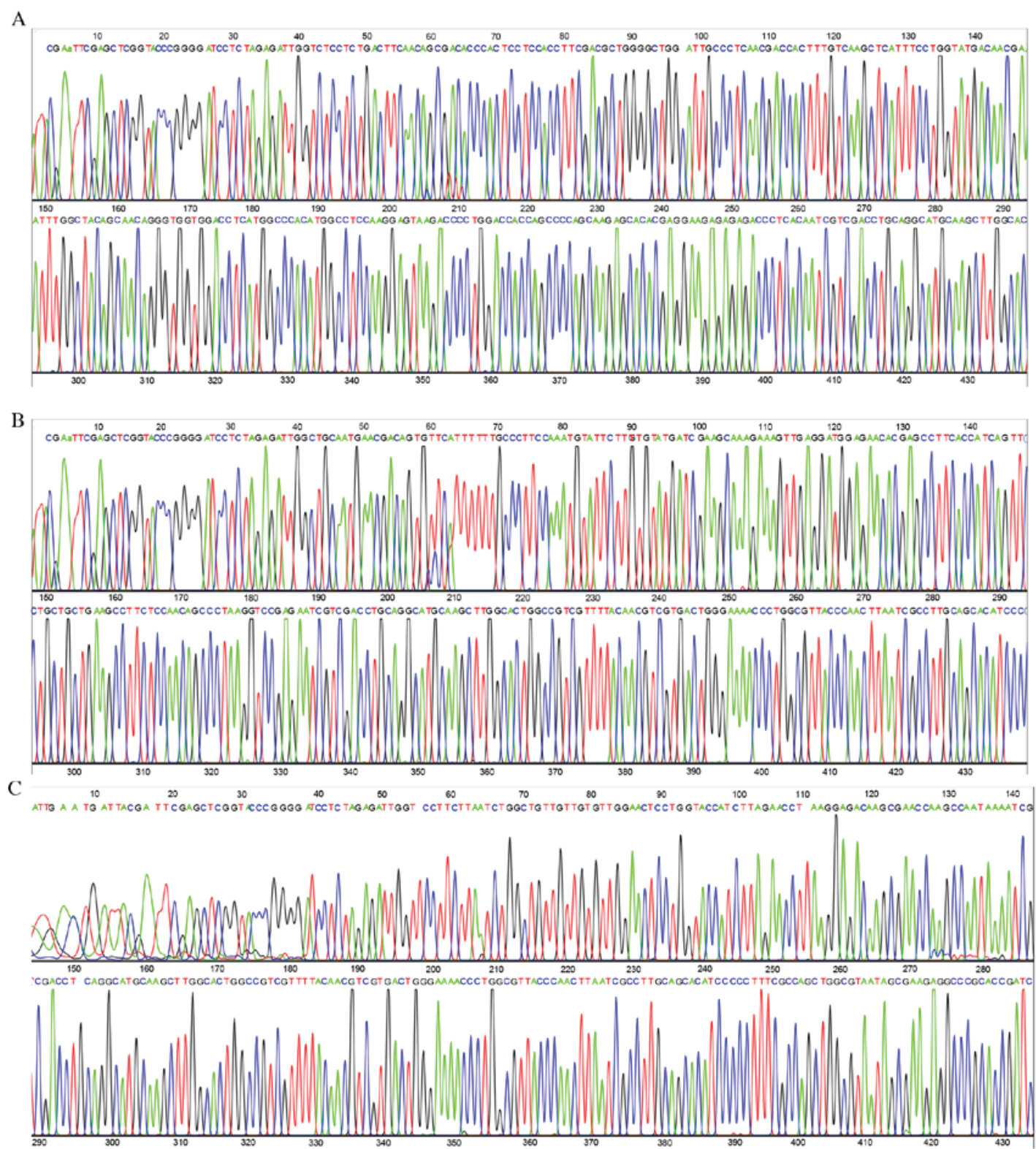

Figure 2. Sequencing results of reverse transcription-quantitative polymerase chain reaction products: (A) Endogenous control, GAPDH, (B) linc00673, (C) linc00312. LincRNA, long intergenic non-coding RNA.

\section{Results}

The validation of linc00312 and linc673 expression in NSCLC. Cancer-related IncRNAs were searched in the LncRNA Disease database (http://www.cuilab.cn/lncrnadisease) with 'NSCLC' as the search term. Based on the previous findings, the authors focused on the two novel lncRNAs (linc00312 and lin00673) and further detected their expression in NSCLC cell lines and tissues. To confirm that linc00312 and linc00673 could be detected by RT-qPCR, the melting curve analysis (Fig. 1) and their PCR product sequence results were available as expected, which were completely consistent with the entries from the NCBI database (Fig. 2).

The expression of linc00312 and linc00673 in NSCLC tissues. Long intergenic non-coding RNA 673 and 312 expression was detected in 76 paired NSCLC samples and corresponding normal tissues by RT-qPCR. The results revealed that the linc00312 was distinctly decreased $(\mathrm{P}<0.001)$, while linc00673 was significantly increased in NSCLC tissues compared with normal tissues $(\mathrm{P}<0.01 ;$ Fig. 3$)$. The waterfall plot demonstrated that linc00312 was reduced by at least three-fold in $59.2 \%$ $(46 / 76)$ of the NSCLC patients. In addition, linc00673 was overexpressed by at least two-fold in 50\% (38/76) of NSCLC patients (Fig. 4). Further statistics analysis indicated that linc00312 was downregulated in both LAD and LSCC tissues compared with the paired normal tissue $(\mathrm{P}<0.001)$. However, linc00673 was extremely upregulated only in LAD patients' tissues $(\mathrm{P}<0.01)$ but not in LSCC cancer tissues $(\mathrm{P}>0.05)$ (Fig. 5). To assess the correlation the expression of linc00673 and linc00312 with clinicopathological data, their expression levels in tumor tissues were categorized as low or high 
A

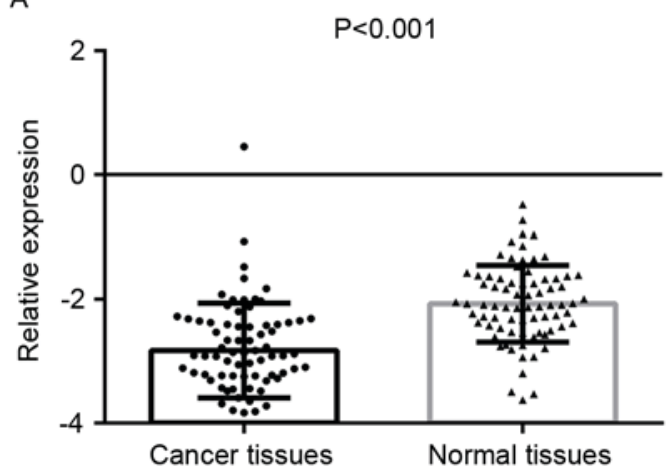

B

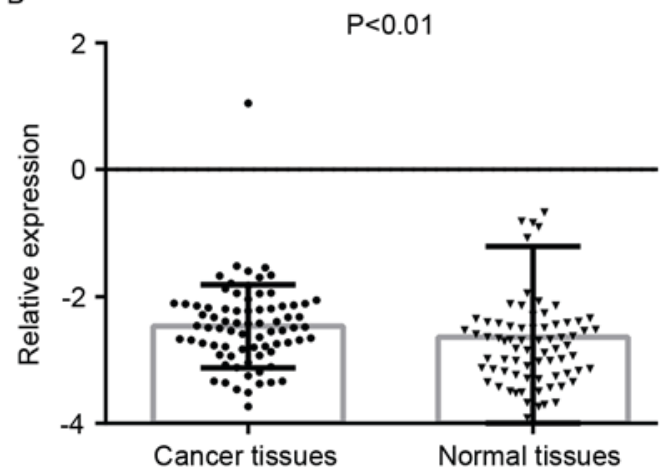

Figure 3. (A) linc00312 was downregulated and (B) linc00673 was upregulated in NSCLC tissues. Long non-coding RNAs expression were examined by reverse transcription-quantitative polymerase chain reaction and normalized to GAPDH expression in 76 pairs of NSCLC tissues, compared with normal tissues. The expression levels were calculated using the $\lg [2(-\Delta \mathrm{CT})]$ method. Values were expressed as mean \pm standard error of the mean. $\mathrm{P}<0.05$ vs. non-tumorous group. NSCLC, non-small cell lung cancer; lincRNA, long intergenic non-coding RNA.

according to the median level. As presented in Table I, the low expression level of linc00312 was associated with the histologic grade of NSCLC patients $(\mathrm{P}<0.05)$, and the high level of linc00673 was related with ADC compared to SCC $(\mathrm{P}<0.05)$. No other significant differences were observed between the expression of the two lncRNAs and the patients' clinical characteristics including age, gender, smoking status, tumor size, advanced T-stage and regional lymph node metastasis.

The expression of linc00312 and linc00673 in NSCLC cell lines. Long intergenic non-coding RNA 673 and 312 expression was detected in four NSCLC cell lines (A549, SPC-A-1, H1299 and 95-D) and HELF by RT-qPCR. The results demonstrated a lower expression of linc00312 in H1299, SPC-A-1, 95-D and A549 cell lines, compared with that in HELF cells (Fig. 6A). Among the six NSCLC cell lines, linc00312 decreased the most in A549 and H1299 cell lines. Moreover, it was identified that linc00673 expressed higher in the four NSCLC cell lines compared with normal lung cell line HELF (Fig. 6B).

ROC curve analysis of linc00312 and linc00673 in tumor tissues. To investigate the diagnostic contribution of the two lncRNA in NSCLC, ROC curve and the area under the ROC curves (AUC) were performed on data from all subjects, including 76 NSCLC patients (Fig. 7). The ROC curves illustrated strong separation between the tumor tissues and control group, with an AUC of 0.803 (95\% CI: 0.732-0.873; P<0.0001) for linc00312 and 0.653 (95\% CI: 0.5663-0.7395; $\mathrm{P}<0.001$ ) for linc00673 respectively (Fig. 7A and B). However, ROC curves was further performed to assess the significance of linc00312 and linc00673 in the subtypes of NSCLC including ADC and SCC compared with their paired non-tumorous groups. The ROC curves indicated that there was strong separation between LAD and paired normal tissues, with an AUC of 0.717 (95\% CI: 0738-0.917; P<0.001) for linc673 (Fig. 7E and F), while the AUC of LSCC for linc00673 was 0.5886 (95\% CI: 0.4534-0.238; $\mathrm{P}=0.203$ ). In addition, there was no difference between the LAD and LSCC group, with an AUC of 0.828 (95\% CI: 0738-0.917; P<0.0001) and 0.7959 (95\% CI: 0.687-0.905; $\mathrm{P}<0.0001$ ) for linc00312, respectively (Fig. 7C and D). Therefore, linc00312 can provided the highly
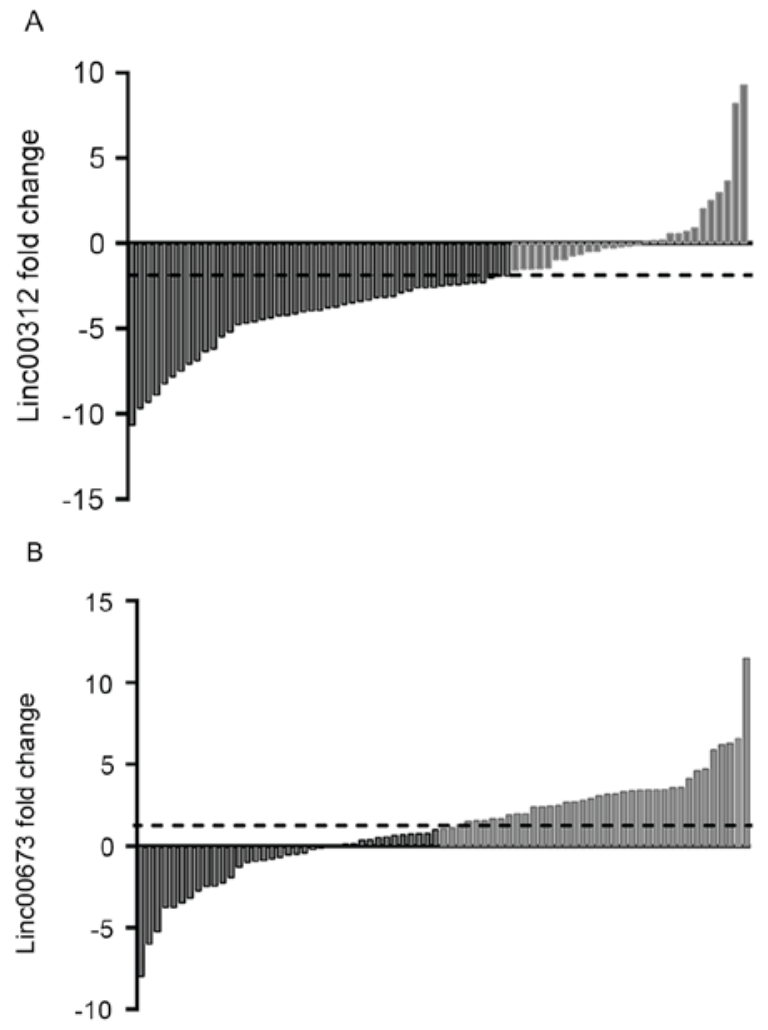

Figure 4. (A) Waterfall plot demonstrated that linc00312 was downregulated in $59.2 \%(46 / 76)$ of human NSCLC samples by at least threefold; (B) and linc00673 was upregulated in 50\% (38/76) of human NSCLC samples by at least two-fold. NT, non-tumorous tissues of NSCLC; NSCLC, non-small cell lung cancer; linc, long intergenic non-coding RNA.

diagnostic power for the detection of NSCLC, while linc00673 may be more specific for LAD.

\section{Discussion}

The early diagnosis of NSCLC is generally poor conducted due to the lack of significantly biomarkers. Recently, micro-RNAs (22) and cyclooxygenase (23) have drawn considerable attention compared with the previous classic tumor 
A

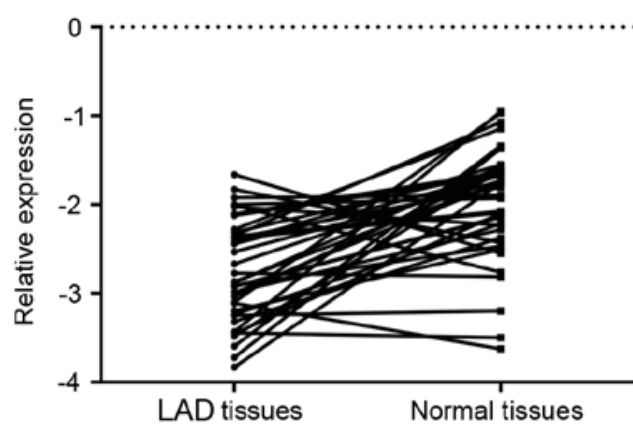

C

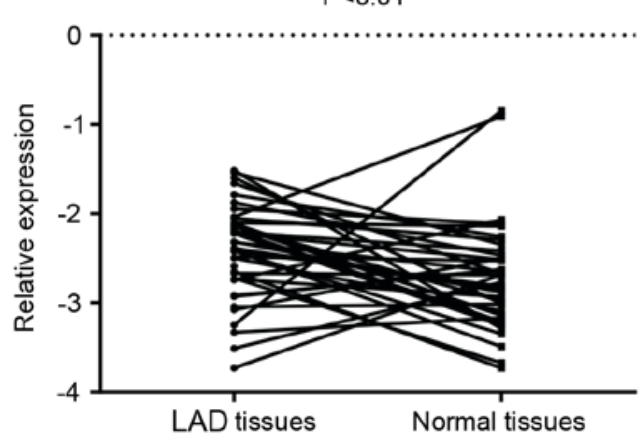

B

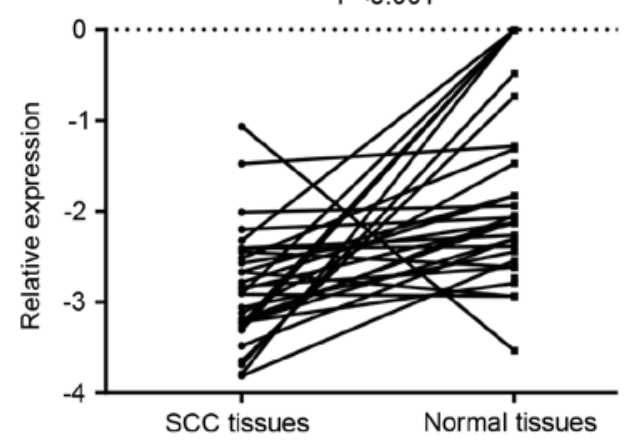

D

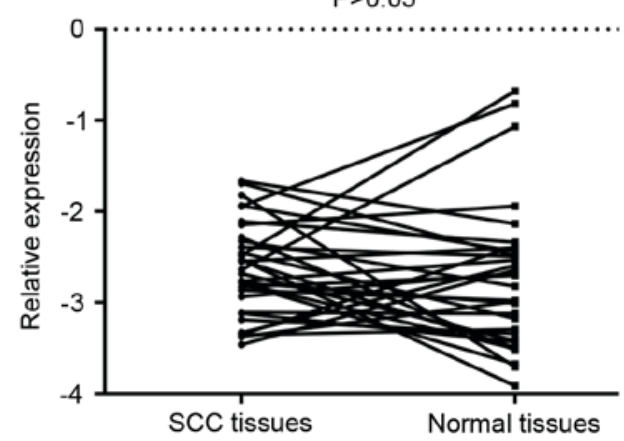

Figure 5. linc00312 decreased both in (A) LAD and (B) LSCC cancer tissues. Linc00673 increased in (C) LAD cancer patients, but not in (D) LSCC cancer tissues. The lncRNA expression was examined by reverse transcription-quantitative polymerase chain reaction, and normalized to GAPDH expression in 43 pairs of LAD tissues and 33 pairs of LSCC tissues, compared with normal tissues. The expression levels were calculated using the $\lg [2(-\Delta C T)]$ method. LincRNA, long intergenic non-coding RNA; LAD, lung adenocarcinoma; LSCC, lung squamous cell carcinoma.

A

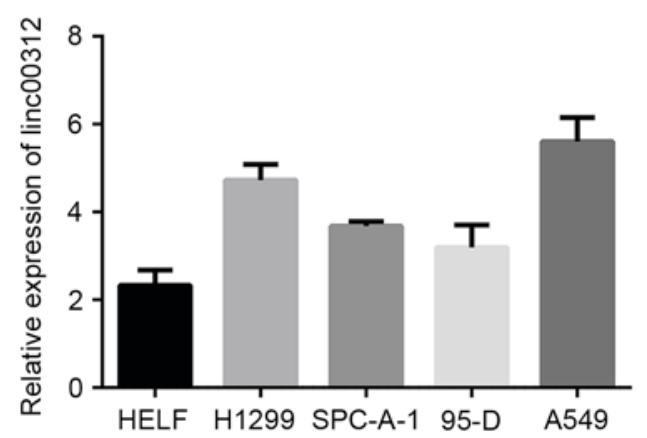

B

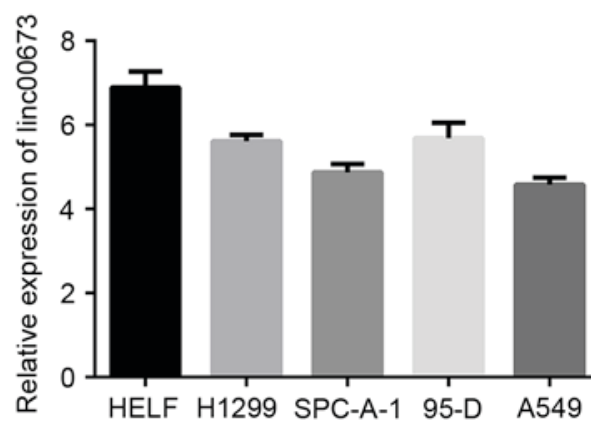

Figure 6. The expression levels of (A) linc00312 and (B) linc00673 in four non-small cell lung cancer cell lines and the normal HELF cell line. Assays were performed in triplicate. Data are presented as mean \pm standard error of the mean. LincRNA, long intergenic non-coding RNA.

markers commonly used in NSCLC treatment. However, the lack of diagnostic sensitivity and specificity appear to be obstacle barrier for their clinical amplification in the early detection of NSCLC.

There are $\sim 15,000$ lncRNAs in the human transcriptome (24). LncRNAs, which have a similar structure to mRNA, are transcribed by polymerase II. Usually, they have fixed polyA tail and promoter, following alternative splicing. Though they contain a lower number of exons than mRNAs and characterized by different, characteristic expression patterns in cancers and other diseases (25-27). On average, IncRNAs, which were considered as 'transcription noise' and 'junk', now has been reported to serve important biological functions in various of diseases and cancers such as cardiovascular disease (28), prostate cancer (29), thyroid cancer (30), hepatocellular carcinoma (31) and gastric cancer (32). So far, quite a few IncRNAs have been better characterized the possible mechanisms involving in chromatin remodeling through multiple chromatin-based mechanisms and RNA cross-talking $(5,33,34)$ and some of which could be prognostic biomarkers and therapeutic targets $(35,36)$. For instance, MALAT-1 generally can be cleaved to small cytoplasmic RNA and large MALAT-1 fragments by RNaseP and RNaseZ, and the latter has the function of epigenetic repression of target genes in cancers through alternative splicing (37); HOTAIR can silence some tumor suppressor genes through H3K27 
A

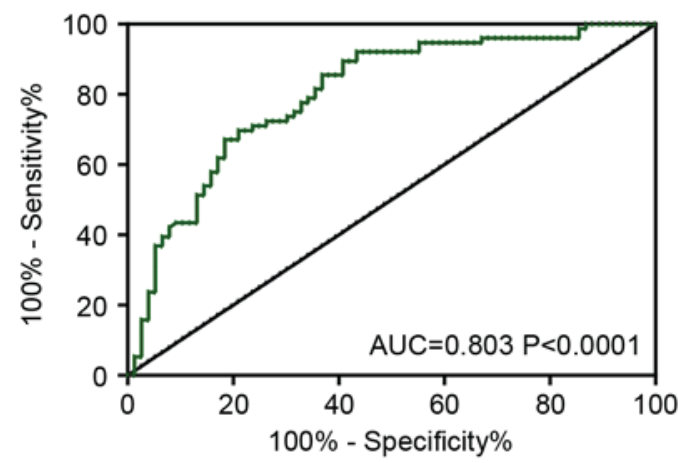

C

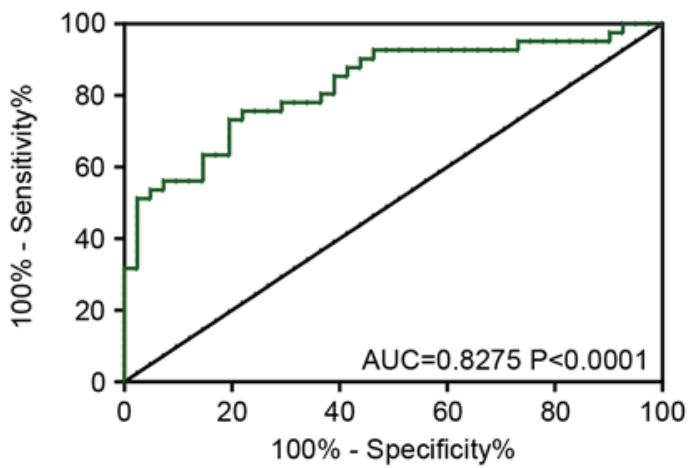

E

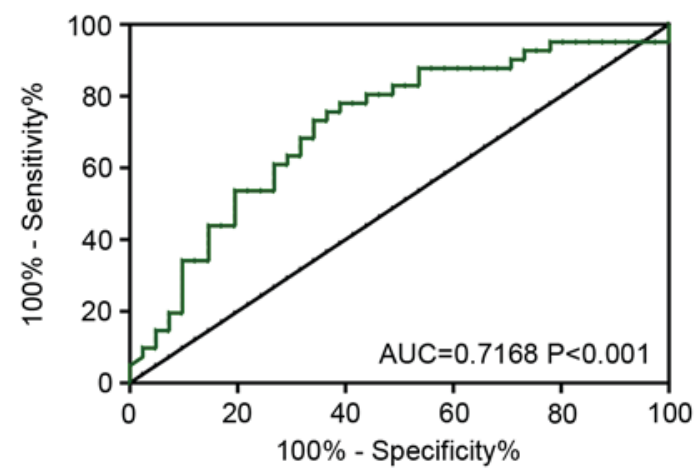

B

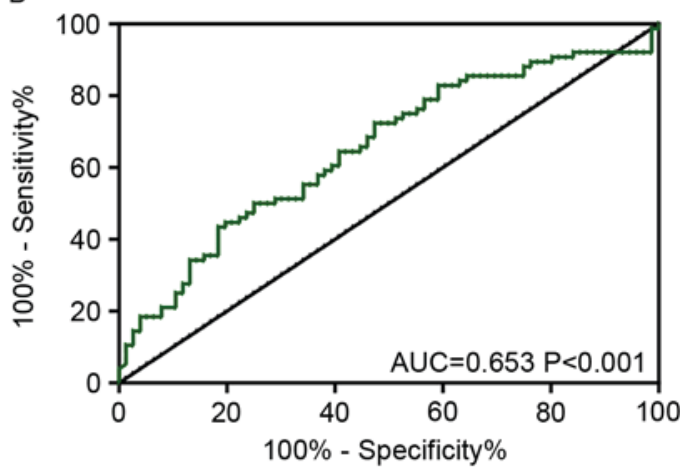

D

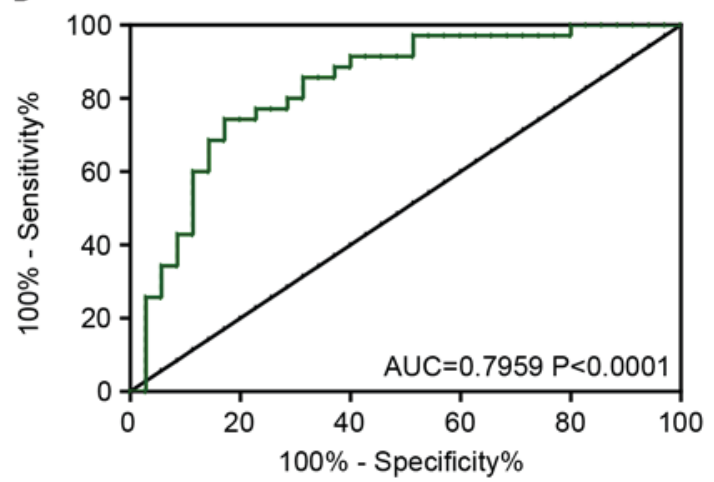

F

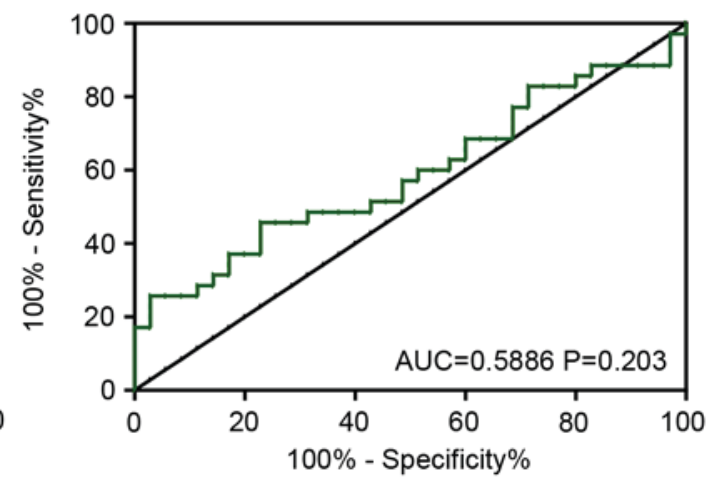

Figure 7. Receiver operator characteristic curve analysis of linc00312 and linc00673 for non-small cell lung cancer. (A) The AUC was 0.803 (95\% CI: 0.732-0.873; P<0.0001) for linc00312; (B) AUC was 0.653 (95\% CI: 0.5663-0.7395; P<0.001) for linc00673; (C) AUC of linc00312 was 0.8275 for LAD (95\% CI: 0738-0.917; P<0.0001); (D) AUC of linc00312 was 0.7959 for LSCC (95\% CI: 0.687-0.905; P<0.001); (E) AUC of linc00673 was 0.7168 for LAD (95\% CI: 0738-0.917; P<0.001); (F) AUC of linc00673 was 0.5886 for LSCC (95\% CI: 0.4534-0.238; P=0.203). AUC, area under curve; lincRNA, long intergenic non-coding RNA; LSCC, lung squamous cell carcinoma; LAD, lung adenocarcinoma.

and H3K4 methylation with the combination of PCR2 and LSD (38). H19 involves in the development of lung cancer by imprint loss and regulation expression of c-myc (39). Those underlying mechanisms of lncRNA have inspired us to identify more specific and valuable lncRNAs. To date, some known lncRNAs have been confirmed to be dysregulated and play functional roles in NSCLC, such as MALAT1, HOTAIR, H19, MEG3, GAS5, ANRIL and SOX2OT $(34,40,41)$, but also many novel lncRNAs. For example, long non-coding RNA 01133 could repress KLF2, P21 and E-cadherin transcription through binding with EZH2, LSD1 and its overexpression is associated with patients' poor prognosis and short survival time in NSCLC (42). Linc00857 may mediate tumor progression through the way of regulating cell cycle in NSCLC (43).
By microarray and RNA-sequencing, high through technology have employed to detect huge number of lung cancer-associated lncRNAs (44), especially LAD and LSCC. In the present study, the authors mainly focused on two intergenic lncRNA 00312 and 00673 and aimed to establish their regulation pattern in NSCLC. Linc00312 locates in the genomic 3p25.3 whose length is $2,903 \mathrm{nt}$ and includes only one exon (18). Linc00312 was originally regarded as mRNA, namely NAG7. A previous study demonstrated that as a protein-coding RNA, it can play critical roles in the interaction of estrogen receptor alpha (ERa) and other molecules including JNK2, c-Fos and MMP-1 (17). However, the HUGO Gene Nomenclature Committee identified that it belongs to the group of long non-coding RNA according to the definition of lncRNAs (18). Although literature has suggested that 
linc00312 could promote nasopharyngeal carcinoma invasion through the JNK2/AP-1/MMP1 signaling pathway (17), its mechanism allowing it to participate in the development and progression of NSCLC remains unclear. No study has been available regarding the relationship between the expression level of linc00312 and the clinicopathological parameters of NSCLC. The present study identified that linc00312 was significantly downregulated in NSCLC patients' tissues compared with normal tissues, including LAD and LSCC. Further statistical analysis revealed that the low expression level of linc00312 was correlated with TNM stage of NSCLC, suggesting that linc00312 could be a potential candidate lncRNA to NSCLC as a suppressor gene. Another lncRNA linc00673 locates at Ch17q25.1 with 2275 bp and consists of four exons and two introns. According to Shi et al (20), linc00673 may participate in the development and progression of NSCLC as an oncogene through silencing NCALD transcription by binding with histone demethylase lysine specific demethylase 1. Furthermore, the authors proved that linc00673 expressed higher in LAD but not in LSCC tissues. In addition, the ROC curve illustrated that linc00673 could be a LAD specific IncRNA as an oncogene. However, no significant relationship was achieved among the expression of linc00312 and linc00673 with patients' other clinical features.

In conclusion, lncRNA 00312 may serve an important role in the tumorigenesis and deterioration of human NSCLC. Moreover, linc00673 is upregulated in LAD but not in LSCC tissues, implying that it can be a potential candidate tissue specific lncRNA for NSCLC.

\section{Acknowledgments}

The present study was supported by the National Basic Research Program of China (973 Program) (grant nos. 2012CB720600 and 2012CB720605).

\section{References}

1. Wu Y, Liu H, Shi X, Yao Y, Yang W and Song Y: The long non-coding RNA HNF1A-AS1 regulates proliferation and metastasis in lung adenocarcinoma. Oncotarget 6: 9160-9172, 2015.

2. Hu T and Lu YR: BCYRN1, a c-MYC-activated long non-coding RNA, regulates cell metastasis of non-small-cell lung cancer. Cancer Cell Int 15: 36, 2015.

3. Yu L, Todd NW, Xing L, Xie Y, Zhang H, Liu Z, Fang H, Zhang J, Katz RL and Jiang F: Early detection of lung adenocarcinoma in sputum by a panel of microRNA markers. Int J Cancer 127: 2870-2878, 2010.

4. Yildiz O, Buyuktas D, Ekiz E, Selcukbiricik F, Papila I and Papila C: Facial nerve palsy: An unusual presenting feature of small cell lung cancer. Case Rep Oncol 4: 35-38, 2011.

5. Tantai J, Hu D, Yang Y and Geng J: Combined identification of long non-coding RNA XIST and HIF1A-AS1 in serum as an effective screening for non-small cell lung cancer. Int J Clin Exp Pathol 8: 7887-7895, 2015.

6. Esteller M: Non-coding RNAs in human disease. Nat Rev Genet 12: 861-874, 2011.

7. Gibb EA, Brown CJ and Lam WL: The functional role of long non-coding RNA in human carcinomas. Mol Cancer 10: 38, 2011.

8. Kaplan R, Luettich K, Heguy A, Hackett NR, Harvey BG and Crystal RG: Monoallelic up-regulation of the imprinted H19 gene in airway epithelium of phenotypically normal cigarette smokers. Cancer Res 63: 1475-1482, 2003.

9. Gutschner T, Hammerle M, Eissmann M, Hsu J, Kim Y, Hung G, Revenko A, Arun G, Stentrup M, Gross M, et al: The noncoding RNA MALAT1 is a critical regulator of the metastasis phenotype of lung cancer cells. Cancer Res 73: 1180-1189, 2013.
10. Zhang E, Li W, Yin D, De W, Zhu L, Sun S and Han L: c-Myc-regulated long non-coding RNA H19 indicates a poor prognosis and affects cell proliferation in non-small-cell lung cancer. Tumour Biol 37: 4007-4015, 2016.

11. Cui D, Yu CH, Liu M, Xia QQ, Zhang YF and Jiang WL: Long non-coding RNA PVT1 as a novel biomarker for diagnosis and prognosis of non-small cell lung cancer. Tumour Biol 37: 4127-4134, 2016

12. Cheng N, Cai W, Ren S, Li X, Wang Q, Pan H, Zhao M, Li J, Zhang Y, Zhao C, et al: Long non-coding RNA UCA1 induces non-T790M acquired resistance to EGFR-TKIs by activating the AKT/mTOR pathway in EGFR-mutant non-small cell lung cancer. Oncotarget 6: 23582-23593, 2015.

13. Shi X, Sun M, Liu H, Yao Y, Kong R, Chen F and Song Y: A critical role for the long non-coding RNA GAS5 in proliferation and apoptosis in non-small-cell lung cancer. Mol Carcinog 54 (Suppl 1): E1-E12, 2015.

14. Lu KH, Li W, Liu XH, Sun M, Zhang ML, Wu WQ, Xie WP and Hou YY: Long non-coding RNA MEG3 inhibits NSCLC cells proliferation and induces apoptosis by affecting p53 expression. BMC Cancer 13: 461, 2013.

15. Sun M, Liu XH, Lu KH, Nie FQ, Xia R, Kong R, Yang JS, Xu TP, Liu YW, Zou YF, et al: EZH2-mediated epigenetic suppression of long noncoding RNA SPRY4-IT1 promotes NSCLC cell proliferation and metastasis by affecting the epithelial-mesenchymal transition. Cell Death Dis 5: e1298, 2014.

16. Jiang W, Zhang D, Xu B, Wu Z, Liu S, Zhang L, Tian Y, Han X and Tian D: Long non-coding RNA BANCR promotes proliferation and migration of lung carcinoma via MAPK pathways. Biomed Pharmacother 69: 90-95, 2015.

17. Huang C, Wu M, Tang Y, Li X, Ouyang J, Xiao L, Li D and Li G: NAG7 promotes human nasopharyngeal carcinoma invasion through inhibition of estrogen receptor alpha and up-regulation of JNK2/AP-1/MMP1 pathways. J Cell Physiol 221: 394-401, 2009.

18. Zhang W, Huang C, Gong Z, Zhao Y, Tang K, Li X, Fan S, Shi L, Li X, Zhang P, et al: Expression of LINC00312, a long intergenic non-coding RNA, is negatively correlated with tumor size but positively correlated with lymph node metastasis in nasopharyngeal carcinoma. J Mol Histol 44: 545-554, 2013.

19. Yu H, Xu Q, Liu F, Ye X, Wang J and Meng X: Identification and validation of long noncoding RNA biomarkers in human non-small-cell lung carcinomas. J Thorac Oncol 10: 645-654, 2015.

20. Shi X, Ma C, Zhu Q, Yuan D, Sun M, Gu X, Wu G, Lv T and Song Y: Upregulation of long intergenic noncoding RNA 00673 promotes tumor proliferation via LSD1 interaction and repression of NCALD in non-small-cell lung cancer. Oncotarget 7: 25558-25575, 2016.

21. Livak KJ and Schmittgen TD: Analysis of relative gene expression data using real-time quantitative PCR and the 2(-Delta Delta C(T)) method. Methods 25: 402-408, 2001.

22. Tejero R, Navarro A, Campayo M, Viñolas N, Marrades RM, Cordeiro A, Ruíz-Martínez M, Santasusagna S, Molins L, Ramirez J and Monzó M: miR-141 and miR-200c as markers of overall survival in early stage non-small cell lung cancer adenocarcinoma. PLoS One 9: e101899, 2014.

23. Shimizu K, Yukawa T, Okita R, Saisho S, Maeda A, Nojima Y and Nakata M: Cyclooxygenase-2 expression is a prognostic biomarker for non-small cell lung cancer patients treated with adjuvant platinum-based chemotherapy. World J Surg Oncol 13: $21,2015$.

24. Koziol MJ and Rinn JL: RNA traffic control of chromatin complexes. Curr Opin Genet Dev 20: 142-148, 2010.

25. Schmitz SU, Grote P and Herrmann BG: Mechanisms of long noncoding RNA function in development and disease. Cell Mol Life Sci 73: 2491-2509, 2016.

26. Derrien T, Johnson R, Bussotti G, Tanzer A, Djebali S, Tilgner H, Guernec G, Martin D, Merkel A, Knowles DG, et al: The GENCODE v7 catalog of human long noncoding RNAs: Analysis of their gene structure, evolution, and expression. Genome Res 22: 1775-1789, 2012.

27. Cabili MN, Trapnell C, Goff L, Koziol M, Tazon-Vega B, Regev A and Rinn JL: Integrative annotation of human large intergenic noncoding RNAs reveals global properties and specific subclasses. Genes Dev 25: 1915-1927, 2011.

28. Ruhle F and Stoll M: Long non-coding RNA databases in cardiovascular research. Genomics Proteomics Bioinformatics 14: 191-199, 2016. 
29. Crea F, Venalainen E, Ci X, Cheng H, Pikor L, Parolia A, Xue H, Nur Saidy NR, Lin D, Lam W, et al: The role of epigenetics and long noncoding RNA MIAT in neuroendocrine prostate cancer. Epigenomics 8: 721-791, 2016.

30. Liu L, Yang J, Zhu X, Li D, Lv Z and Zhang X: Long noncoding RNA H19 competitively binds miR-17-5p to regulate YES1 expression in thyroid cancer. FEBS J 283: 2326-2339, 2016.

31. Chang L, Wang G, Jia T, Zhang L, Li Y, Han Y, Zhang K, Lin G, Zhang R, Li J and Wang L: Armored long non-coding RNA MEG3 targeting EGFR based on recombinant MS2 bacteriophage virus-like particles against hepatocellular carcinoma. Oncotarget 7: 23988-24004, 2016.

32. Li CY, Liang GY, Yao WZ, Sui J, Shen X, Zhang YQ, Peng H, Hong WW, Ye YC, Zhang ZY, et al: Integrated analysis of long non-coding RNA competing interactions reveals the potential role in progression of human gastric cancer. Int J Oncol 48: 1965-1976, 2016

33. Huarte M, Guttman M, Feldser D, Garber M, Koziol MJ, Kenzelmann-Broz D, Khalil AM, Zuk O, Amit I, Rabani M, et al: A large intergenic noncoding RNA induced by p53 mediates global gene repression in the p53 response. Cell 142: 409-419, 2010.

34. Loewer S, Cabili MN, Guttman M, Loh YH, Thomas K, Park IH, Garber M, Curran M, Onder T, Agarwal S, et al: Large intergenic non-coding RNA-RoR modulates reprogramming of human induced pluripotent stem cells. Nat Genet 42: 1113-1117, 2010.

35. Gao J, Cao R and Mu H: Long non-coding RNA UCA1 may be a novel diagnostic and predictive biomarker in plasma for early gastric cancer. Int J Clin Exp Pathol 8: 12936-12942, 2015

36. Wu Y, Yu DD, Hu Y, Yan DL, Chen X, Zhang HD, Cao HX, Yu SR, Wang Z and Feng JFX: The long non-coding RNA, LINC00635-001, sensitizes EGFR-TKI-resistant human lung cancer cells in vitro by inhibiting Akt activation. Biochem Biophys Res Commun: Jan 11, 2016 (Epub ahead of print).
37. Wilusz JE, Freier SM and Spector DL: 3' end processing of a long nuclear-retained noncoding RNA yields a tRNA-like cytoplasmic RNA. Cell 135: 919-932, 2008

38. Tsai MC, Manor O, Wan Y, Mosammaparast N, Wang JK, Lan F, Shi Y, Segal E and Chang HY: Long noncoding RNA as modular scaffold of histone modification complexes. Science 329: 689-693, 2010.

39. Venkatraman A, He XC, Thorvaldsen JL, Sugimura R, Perry JM, Tao F, Zhao M, Christenson MK, Sanchez R, Yu JY, et al: Maternal imprinting at the H19-Igf2 locus maintains adult haematopoietic stem cell quiescence. Nature 500: 345-349, 2013.

40. Sang $\mathrm{H}$, Liu $\mathrm{H}$, Xiong $\mathrm{P}$ and Zhu M: Long non-coding RNA functions in lung cancer. Tumour Biol 36: 4027-4037, 2015

41. Du Z, Fei T, Verhaak RG, Su Z, Zhang Y, Brown M, Chen Y and Liu XS: Integrative genomic analyses reveal clinically relevant long noncoding RNAs in human cancer. Nat Struct Mol Biol 20: 908-913, 2013.

42. Zang C, Nie FQ, Wang Q, Sun M, Li W, He J, Zhang M and Lu KH: Long non-coding RNA LINC01133 represses KLF2, P21 and E-cadherin transcription through binding with EZH2, LSD1 in non small cell lung cancer. Oncotarget 7: 11696-11707, 2016.

43. Wang L, He Y, Liu W, Bai S, Xiao L, Zhang J, Dhanasekaran SM, Wang Z, Kalyana-Sundaram S, Balbin OA, et al: Non-coding RNA LINC00857 is predictive of poor patient survival and promotes tumor progression via cell cycle regulation in lung cancer. Oncotarget 7: 11487-11499, 2016.

44. Chung S, Nakagawa H,Uemura M,Piao L, Ashikawa K, Hosono N, Takata R, Akamatsu S, Kawaguchi T, Morizono T, et al: Association of a novel long non-coding RNA in 8q24 with prostate cancer susceptibility. Cancer Sci 102: 245-252, 2011. 